\title{
National Survey of Hospital Medication Safety Practice during Mass Gathering (Hajj-2016) in Makkah, Saudi Arabia: Environmental Culture and Staff Competency
}

\author{
Yousef Ahmed Alomi ${ }^{1 *}$, Nezar Adnan Yahya Khayat ${ }^{2}$, Mustafa Jamil Baljoon², Yasir Abdulraheem \\ Bamagaus $^{3}$, Hani Mohammed Ali Jumah ${ }^{3}$ \\ ${ }^{I}$ The Past General Manager of General Administration of Pharmaceutical Care and Head, National Clinical \\ pharmacy, pharmacy practice and Pharmacy $R$ \& D Administration, Ministry of Health, Riyadh, KSA
}

${ }^{2}$ General Director, Makkah Health Affairs Region, Makkah, KSA

${ }^{3}$ Pharmaceutical Care Administration, Makkah Medical Affairs Region, Makkah, KSA

Received: 13 August 2017;
Accepted: 28 September 2017
*Correspondence to:
Dr. Yousef Ahmed Alomi, The Past General Manager of General Administration of Pharmaceutical Care, Head, National Clinical pharmacy, and Pharmacy practice, and Pharmacy $R \& D$ Administration, Ministry of Health, Riyadh 11392, Kingdom of SAUDI ARABIA (KSA)

Email:yalomi@gmail.com

Copyright: (C) the author(s),publisher and licensee Indian Academy of Pharmacists. This is an openaccess article distributed under the terms of the Creative Commons Attribution Non-Commercial License, which permits unrestricted non-commercial use, distribution, and reproduction in any medium, provided the original work is properly cited.
Abstract

Objective: To explore the national survey of hospital medication safety practice during mass gathering (Hajj -2016) in Makkah, Saudi Arabia: Environmental factors and staff competency, the finding of ISMP (2011) self-assessment of medication safety at the hospitals. Methods: It is 15 days cross-sectional national survey of hospital medication safety at Makkah region. The survey modified from Institution of Safe Medication Practice (ISMP) self-assessment of hospital medication safety. It consisted of a demographic section and ten domains with 270 questions. The ten areas included patient information, drug information, communication of medication orders, drug preparation, medication distribution, medication devices, work environment, staff competency, patient education, quality process with risk management domain. The 5-points Likert response scale system used. The survey distributed to sixteen directors of hospital pharmacy during mass gathering Hajj-2016. The medications safety officer at Makkah region distributed the questionnaire and made follow up on a daily basis used physical visiting and through the telephone call. Results: The survey distributed to sixteen hospitals, the response rate, was eleven hospitals (68.75\%). The total score of all ISMP-self assessment of medication safety was $3.39+/-0.51(67.68 \%)$ with $\mathrm{Cl}(3.2-3.6) \mathrm{P}<0.05$. The average rating of environmental factors, workflow, and staffing were 3.93 (78.6 \%) while the mean score staff competency and education domain at all hospital were $3.6959 .40 \%$ ). The highest score of both domains was a standard lighting adequate to read labels and other important drug and patient information in pharmacies 4.70 (94\%). The lowest score of both domains was The organization provides formal teamwork training to all staff 2.91 (58.2\%). Conclusion: The medication safety related environmental factors, workflow, and staff competency key element during mass gathering Hajj period was right level. The levels of both domains required to continue in the coming next years with focusing on using the new technology of pharmacy practice at hospitals and annual assessment medication safety culture during mass gathering Hajj period at all hospitals in Makka region, Saudi Arabia highly recommended.

Key words: Medication Safety, Hajj, Environmental, Staff, Competency, Ministry of Health, Saudi Arabia. 


\section{INTRODUCTION}

General Administration of Pharmaceutical Care (GAPC) at the ministry of health in Saudi Arabia released medical and non-medical equipment pharmacy guideline, national pharmacy competency system, and a new standard of pharmacy manager requirements for hospitals and primary care centers. ${ }^{[1-3]}$ All those programs complemented to the national medication safety program. ${ }^{[4]}$ The supporting program increased medication safety weather and prevented drug related problems of the patient at any specialty of the institution. All previous program applied during mass gathering hajj period. ${ }^{[5]}$ It seldom to find local studies a bout pharmacy competency or environmental factors or pharmacy workforce related to medication safety in Saudi Arabia. Institute for Safe Medication Practice (ISMP) in the United States of America (USA) had released excellent tools to measure the medication safety and relationship with environmental workflow and staff competency. ${ }^{[6]}$ The first issues were in 2000 and then updated in 2011. The ISMP did studies to measure in reality at USA hospital those key elements. The authors found the environmental factors, workflow, staffing key element changed from $70 \%$ to $77 \%$, and staff competency and education key element improved from 53\% to $64 \%$. ${ }^{[7-9]}$ The authors are not familiar with any published study about those key elements and medication safety relationship in Saudi Arabia, Gulf or even Middle East countries, especially during mass gathering hajj period. The objective of our study to explore the medication safety practice during mass gathering (Hajj -2016) in Makkah hospitals, Saudi Arabia: Environmental factors and staff competency, the finding of ISMP (2011) selfassessment of medication safety at the hospital.

\section{METHODS}

It is a fifteen days cross-sectional national survey of hospital medication safety at Makkah region. The survey modified from Institution of Safe Medication Practice (ISMP) self-assessment of hospital medication safety. It consisted of a demographic section and ten domains with 270 questions. The ten areas included patient information, drug information, communication of drug orders and other drug information, drug Labeling and Packaging and Nomenclature, drug standardization, storage and distribution, medication devices acquisition, use, and monitoring. The environmental factors, workflow, and staffing, staff competency, patient education, quality processes and risk management domain. It contained a twenty core sections included essential patient information, essential drug information, a controlled drug formulary system, methods of communicating drug orders, strategies to minimize the possibility of errors. The clear labels that identify drugs are on all drug containers, standardized of IV solutions, drug concentrations, doses, and administration times. A safety-supportive culture, practitioners are stimulated to detect and report adverse events, errors, hazards, and observed at risk behavior, and redundancies that support a system of independent double check at risk. The practitioners receive sufficient orientation to medication use; the practitioners involved in medication use provided with ongoing education about medication error prevention and the safe use, patients, are included as active partners. Medications provided to patient care units safely and securely, the unit stock, is restricted, hazardous chemicals safely sequestered, the potential for human errors, medications are prescribed, transcribed, prepared, dispensed, and administered within an efficient and safe workflow. The complement of qualified, wellrested practitioners matches the clinical workload without compromising patient safety.

The 5-points Likert response scale system used. The scoring key identified as number (1) equal to (A): No activity to implement, (2) equal to (B): Considered, but not implemented, (3) equal to (C): partially implemented in some or all areas. (4) Equal to (D): Fully implemented in some areas, and (5) equal to (E): Fully implemented throughout. The survey conducted at a permanent and temporary hospital located at Makkah and holy places. Most of the hospital had outpatient, and emergency services, some of them had critical care section for adults, pediatrics, and internal medicine.

The hospital provided emergency and outpatient pharmacies, inpatient pharmacies. Some of the hospitals had intravenous admixture and total parenteral services and drug information services. Structural Clinical pharmacy services missed at most of the hospitals except critical care pharmacy and stewardship antimicrobial program at permanent hospitals, some essential Clinical pharmacy program; pain management, and anticoagulation program not existed at all hospital. The survey distributed to directors of hospital pharmacy during mass gathering Hajj-2016.

The medications safety officer at Makkah region distributed the questionnaire and made follow up on a daily basis used physical visiting and through the telephone call. The study made as an electronic format, 
and it analyzed through survey monkey system and Microsoft Excel version ten. The authors suggested some solution to improve the scoring medication safety culture and the finding of ISMP self-assessment, the 5-points Likert scale system with high priority or opportunity to implement (5) and low priority or opportunity to implement (1). Those suggestions based on General Administration of Pharmaceutical strategic goals and Saudi Central Board of Accreditation for Health Care Institutions (CBAHI) standards in Saudi Arabia. The ten domains divided into for several parts for analysis, discussion, and solutions. Part one: patient information, part two: drug information, part three: medication preparation and dispensing (communication of drug orders and other drug information, drug Labeling and Packaging and Nomenclature). The part four: medication administration (drug standardization, storage and distribution, medication devices acquisition, use, and monitoring), part five: environmental factors, workflow, and staffing, staff competency, and part six: patient education, quality processes, and risk management. The study explored the part number five; it is a finding from ISMP (2011) medication safety at a hospital in Makkah.

\section{RESULTS}

The survey distributed to sixteen hospitals, the response rate, was eleven hospitals $(68.75 \%)$. The number of permanent hospitals was six (54.45\%) located at Makkah city while the temporary hospitals were five (45.45\%) located at holy places. Of those four $(36.4 \%)$ hospitals bed size was (100-199) and 3 (27.3\%) bed size (200-299). The number of hospitals accredited by Saudi Central Board of Hospitals Accreditation (CIBAHI) was four $(36.4 \%)$ while three hospitals $(27.3 \%)$ accredited by USA International Joint Commission and CIBAHI. The total number of prescriptions was $(120,598)$. Of those $(72,627)$ were Ambulatory care prescriptions, while $(43,242)$ were Emergency Prescriptions, and $(4,729)$ were inpatient orders. The total number of the pharmacist was (180) while pharmacy technician (83) and a number of clinical pharmacists not reported as explored in Table 1.

The total score of all ISMP-self assessment of medication safety was $3.39+/-0.51(67.68 \%)$ with CI (3.2-3.6) $\mathrm{P}<$ 0.05 and range $(2.75-3.93)$. 2. The average score of Environmental Factors, Workflow, and Staffing were $3.93+/-0.44(78.6 \%)$ with CI (3.73-4.13), P< 0.05 and range $(3.36-4.70)$. The average score Staff competency

\begin{tabular}{|c|c|c|c|c|c|c|c|c|c|c|c|c|c|}
\hline \multirow[b]{2}{*}{$\begin{array}{l}\text { No a n d } \\
\text { Hospitals }\end{array}$} & \multirow[b]{2}{*}{ Location } & \multirow[b]{2}{*}{$\begin{array}{c}\text { Hospital } \\
\text { Type }\end{array}$} & \multirow[b]{2}{*}{$\begin{array}{l}\text { No of } \\
\text { Beds }\end{array}$} & \multirow[b]{2}{*}{ 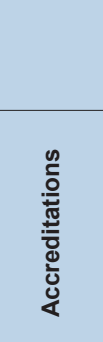 } & \multirow[b]{2}{*}{ 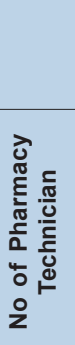 } & \multirow[b]{2}{*}{$\begin{array}{l}\frac{\pi}{0} \\
\frac{0}{0} \\
\frac{\pi}{0} \\
\frac{E}{\pi} \\
\frac{\pi}{0} \\
\frac{c}{0} \\
\frac{0}{0} \\
0 \\
\frac{0}{Z}\end{array}$} & \multirow[b]{2}{*}{ 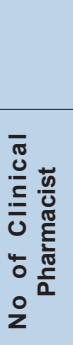 } & \multicolumn{2}{|c|}{$\begin{array}{c}\text { No of OPD } \\
\text { Prescriptions }\end{array}$} & \multicolumn{2}{|c|}{$\begin{array}{c}\text { No of } \\
\text { Emergency } \\
\text { Prescriptions }\end{array}$} & \multicolumn{2}{|c|}{$\begin{array}{c}\text { No of } \\
\text { Inpatient } \\
\text { Prescriptions }\end{array}$} \\
\hline & & & & & & & & $\frac{\stackrel{n}{E}}{\frac{D}{2}}$ & 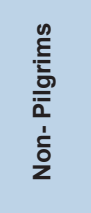 & $\frac{\stackrel{n}{E}}{\frac{5}{2}}$ & 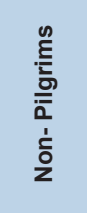 & $\frac{\stackrel{n}{E}}{\frac{\text { 흘 }}{2}}$ & 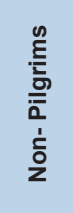 \\
\hline 1.Mena-1 & Mena & Temporary & $100-199$ & Non & 9 & 1 & NR & 6,180 & 500 & 992 & 67 & 179 & 6 \\
\hline 2. Mena-2 & Mena & Temporary & $100-199$ & Non & 18 & 1 & NR & 15,203 & 330 & 1,661 & 113 & 612 & 17 \\
\hline 3. Mena-3 & Mena & Temporary & 200-299 & Non & 19 & 2 & NR & 12,286 & 1,016 & 1,281 & 99 & 350 & 22 \\
\hline 4. Arafat-1 & Arafat & Temporary & $200-299$ & Non & 10 & 1 & NR & 527 & 73 & 272 & 22 & 129 & 6 \\
\hline 5. Arafat-2 & Arafat & Temporary & $100-199$ & Non & 8 & 1 & NR & 4,073 & 155 & 328 & 13 & 192 & 6 \\
\hline 6. M-1 & Makkah & Permanent & $300-399$ & CIBAHI & 12 & 9 & NR & 22 & 650 & 244 & 6,135 & 31 & 664 \\
\hline 7. M-2 & Makkah & Permanent & 200-299 & $\begin{array}{l}\text { CIBAHI - } \\
\text { JCI }\end{array}$ & 23 & 10 & NR & 34 & 3,208 & 185 & 9,408 & 46 & 728 \\
\hline 8. M-3 & Makkah & Permanent & $400-599$ & $\begin{array}{c}\text { CIBAHI - } \\
\text { JCI }\end{array}$ & 60 & 24 & NR & 6,706 & 15,222 & 4,033 & 4,026 & 428 & 490 \\
\hline 9. M-4 & Makkah & Permanent & $50-99$ & $\mathrm{JCl}$ & 7 & 2 & NR & 0 & 0 & 1,754 & 1,159 & 55 & 11 \\
\hline 10. M-5 & Makkah & Permanent & $100-199$ & CIBAHI & 4 & 2 & NR & 1,037 & $N R$ & 3,353 & NR & 29 & $N R$ \\
\hline 11. M-6 & Makkah & Permanent & 300-399 & CIBAHI & 10 & 30 & NR & 2,640 & 2,765 & 2,988 & 5,109 & 411 & 317 \\
\hline Total & & & & & 180 & 83 & & 48,708 & 23,919 & 17,091 & 26,151 & 2,462 & 2,267 \\
\hline \multicolumn{14}{|c|}{ Total no of prescriptions $=120598$} \\
\hline No.: Number, & Vot reporte & & & & & & & & & & & & \\
\hline
\end{tabular}


Alomi et al.: Medication Safety during Hajj: Environmental culture and staff competency.

\begin{tabular}{|c|c|c|c|c|c|c|c|c|c|}
\hline $\begin{array}{c}\text { Core } \\
\#\end{array}$ & Core Characteristic & $\begin{array}{l}\text { Mean } \\
\text { score }\end{array}$ & SD & Range & Percent & SD \% & Range \% & $\begin{array}{l}\text { U S A } \\
2000 \\
\text { Scores } \\
\quad \%\end{array}$ & 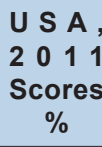 \\
\hline VII & $\begin{array}{l}\text { Environmental Factors, Workflow, } \\
\text { and Staffing }\end{array}$ & 3.93 & 0.44 & $3.36-4.70$ & 78.60 & 8.80 & $67.20-94.00$ & 70.00 & 77.00 \\
\hline 12 & $\begin{array}{l}\text { Efficient and safe workflow in increase } \\
\text { distraction-free environment with } \\
\text { adequate space and lighting }\end{array}$ & 4.01 & 0.527 & $3.45-4.70$ & 80.20 & 10.54 & $69.00-94.00$ & 69.00 & 74.00 \\
\hline 13 & $\begin{array}{l}\text { The complement of qualified, } \\
\text { well-rested practitioners matches } \\
\text { the clinical workload without } \\
\text { compromising patient safety }\end{array}$ & 3.86 & 0.367 & $3.36-4.36$ & 77.20 & 3.67 & $67.20-87.20$ & 71.00 & 80.00 \\
\hline VIII & Staff competency and education & 3.69 & 0.445 & $2.91-4.40$ & 73.80 & 8.90 & $58.20-88.00$ & 53.00 & 64.00 \\
\hline 14 & $\begin{array}{l}\text { Sufficient orientation and baseline } \\
\text { and increase annual competency } \\
\text { evaluations }\end{array}$ & 3.67 & 0.51 & $2.91-4.40$ & 73.40 & 10.20 & $58.20-88.00$ & 56.00 & 67.00 \\
\hline 15 & $\begin{array}{l}\text { Ongoing education about medication } \\
\text { increase error prevention and safe } \\
\text { use of drugs }\end{array}$ & 3.72 & 0.36 & $3.18-4.18$ & 74.40 & 7.20 & $63.60-83.60$ & 49.00 & 59.00 \\
\hline
\end{tabular}

\begin{tabular}{|c|c|c|c|c|c|c|c|c|c|}
\hline \multicolumn{10}{|c|}{ VII: Environmental Factors, Workflow, and Staffing } \\
\hline \multirow[t]{3}{*}{$\begin{array}{l}\sum_{0}^{0} \\
\sum_{\underline{0}}^{0} \\
\underline{0}\end{array}$} & Key elements & $\begin{array}{l}\text { A } \\
1\end{array}$ & $\begin{array}{l}B \\
2\end{array}$ & $\begin{array}{l}C \\
3\end{array}$ & $\begin{array}{l}D \\
4\end{array}$ & $\begin{array}{l}E \\
5\end{array}$ & 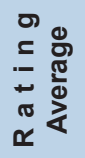 & 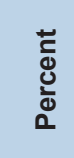 & 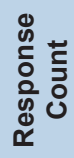 \\
\hline & $\begin{array}{l}\text { Core \# 12: Efficient and safe workflow in increase distraction-free environment with adequate space } \\
\text { and lighting }\end{array}$ & & & & & & & & \\
\hline & The highest scores items & & & & & & & & \\
\hline 149 & Lighting is adequate to read labels and other important drug and patient information & 0 & 0 & 1 & 1 & 8 & 4.70 & 94.00 & 10 \\
\hline \multirow[t]{2}{*}{157} & $\begin{array}{l}\text { Practitioners who administer medications prepare and/or select one patient's medications at a time, } \\
\text { immediately before administering the drug. }\end{array}$ & 1 & 0 & 0 & 0 & 9 & 4.60 & 92.00 & \\
\hline & The lowest scores items & & & & & & & & \\
\hline 154 & $\begin{array}{l}\text { Areas, where drug orders transcribed and/or entered into computer order entry systems isolated and } \\
\text { relatively free of distractions, interruptions, and noise }\end{array}$ & 3 & 0 & 1 & 1 & 5 & 3.50 & 70.00 & 10 \\
\hline \multirow[t]{3}{*}{158} & $\begin{array}{l}\text { When new construction or renovation of an existing area when prescribed, dispensed, stored, or } \\
\text { administered planned, an interdisciplinary group of practicing staff involved in medication use }\end{array}$ & 4 & 0 & 0 & 1 & 6 & 3.45 & 69.00 & 11 \\
\hline & $\begin{array}{l}\text { Core \# 13: The complement of qualified, well-rested practitioners matches the clinical workload } \\
\text { without compromising patient safety }\end{array}$ & & & & & & & & \\
\hline & The highest scores items & & & & & & & & \\
\hline 162 & Schedules and workload permit practitioners involved in the medications process & 1 & 0 & 1 & 1 & 8 & 4.36 & 87.20 & 11 \\
\hline 163 & $\begin{array}{l}\text { An effective backup plan established for days when staffing is short due to illness, vacation, } \\
\text { educational absences, and fluctuations in patient acuity and workload. }\end{array}$ & 1 & 0 & 1 & 2 & 7 & 4.27 & 85.40 & 11 \\
\hline \multirow[t]{2}{*}{164} & $\begin{array}{l}\text { Pharmacists and pharmacy technicians believe that staffing patterns in their department are adequate } \\
\text { to provide safe pharmaceutical care on most days. }\end{array}$ & 1 & 0 & 2 & 0 & 8 & 4.27 & 85.40 & 11 \\
\hline & The lowest scores items & & & & & & & & \\
\hline 167 & $\begin{array}{l}\text { The organization has an adequate complement of well-qualified and trained nurses to provide care } \\
\text { to specialty populations }\end{array}$ & 3 & 1 & 0 & 2 & 5 & 3.45 & 69.00 & 11 \\
\hline \multirow[t]{2}{*}{166} & $\begin{array}{l}\text { The pharmacy department has an adequate complement of trained and dedicated personnel to meet } \\
\text { the medication-related technology requirements }\end{array}$ & 4 & 0 & 0 & 2 & 5 & 3.36 & 67.20 & 11 \\
\hline & answered question 11 and question 0 & & & & & & & & \\
\hline
\end{tabular}

and education domain at all hospital were $3.69+/$ $0.45(59.40 \%)$ with CI $(3.51-3.87), \mathrm{P}<0.05$ and range $(2.91-4.40)$ as explored in Table 2.

The highest score of the Environmental Factors, Workflow, and Staffing was a Standard Lighting adequate to read labels and other important drug and patient information in pharmacies 4.70 (94\%). The lowest score was the pharmacy department has an adequate complement of trained and dedicated personnel to meet the medication-related technology requirements $3.36(67.2 \%)$, and all detail results with 


\begin{tabular}{|c|c|c|c|c|c|c|c|c|c|}
\hline \multicolumn{10}{|c|}{ VIII: Staff competency and education } \\
\hline \multirow[t]{3}{*}{ 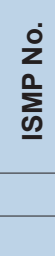 } & Key elements & $\begin{array}{l}\text { A } \\
1\end{array}$ & $\begin{array}{l}\text { B } \\
2\end{array}$ & $\begin{array}{l}\text { C } \\
3\end{array}$ & $\begin{array}{l}\text { D } \\
4\end{array}$ & $\begin{array}{l}\mathbf{E} \\
5\end{array}$ & $\begin{array}{l}\text { ర) } \\
=\frac{0}{0} \\
=\frac{\pi}{0} \\
\approx \\
\approx\end{array}$ & 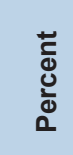 & 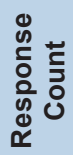 \\
\hline & Core \# 14: Sufficient orientation and baseline and increase annual competency evaluations & & & & & & & & \\
\hline & The highest scores items & & & & & & & & \\
\hline 170 & $\begin{array}{l}\text { A defined period of orientation and training of agency staff required before they can work } \\
\text { independently. }\end{array}$ & 0 & 1 & 1 & 1 & 7 & 4.40 & 88.00 & 10 \\
\hline \multirow[t]{2}{*}{172} & $\begin{array}{l}\text { During orientation, the staff participating in the medication use process, receive information about the } \\
\text { hospital's actual error experiences as well as published errors }\end{array}$ & 0 & 1 & 2 & 1 & 6 & 4.20 & 84.00 & 10 \\
\hline & The lowest scores items & & & & & & & & \\
\hline 173 & $\begin{array}{l}\text { During orientation, nurses spend time in the pharmacy to become familiar with the order entry and/or } \\
\text { verification process, drug preparation and dispensing, availability of drug information resources }\end{array}$ & 2 & 2 & 2 & 1 & 3 & 3.10 & 62.00 & 10 \\
\hline 182 & $\begin{array}{l}\text { The hospital information technology department/staff includes personnel with specialty training in } \\
\text { clinical informatics }\end{array}$ & 3 & 0 & 3 & 1 & 3 & 3.10 & 62.00 & 10 \\
\hline \multirow[t]{3}{*}{183} & The organization provides formal teamwork training to all staff & 4 & 0 & 3 & 1 & 3 & 2.91 & 58.20 & 11 \\
\hline & Core \# 15: Ongoing education about medication increase error prevention and safe use of drugs & & & & & & & & \\
\hline & The highest scores items & & & & & & & & \\
\hline 185 & $\begin{array}{l}\text { Pharmacists routinely provide nurses and other practitioners who administer medications with } \\
\text { valuable information about non-formulary drugs before dispensing the products to the patient. }\end{array}$ & 1 & 0 & 2 & 1 & 7 & 4.18 & 83.60 & 11 \\
\hline \multirow[t]{2}{*}{184} & $\begin{array}{l}\text { Practitioners educated about new drugs added to the formulary and associated protocols/guidelines } \\
\text { and restrictions before the drugs used in the hospital. }\end{array}$ & 1 & 0 & 1 & 3 & 5 & 4.10 & 82.00 & 10 \\
\hline & The lowest scores items & & & & & & & & \\
\hline 194 & $\begin{array}{l}\text { Senior leaders, management, and frontline staff receive formal training in identifying risk within the } \\
\text { system }\end{array}$ & 4 & 0 & 1 & 2 & 4 & 3.18 & 63.60 & 11 \\
\hline \multirow[t]{2}{*}{192} & $\begin{array}{l}\text { Simulations of error-prone conditions used as methodologies to orient and educate practitioners and } \\
\text { other staff about medication/patient safety. }\end{array}$ & 3 & 1 & 2 & 1 & 4 & 3.18 & 63.60 & 11 \\
\hline & answered question 11 and skipped question 0 & & & & & & & & \\
\hline
\end{tabular}

all cores explored in Table 3. The highest score of Staff competency and education key element was a defined period for orientation and training of agency staff is required before they can work independently 4.4 (88\%). The lowest score was the Simulations of error-prone conditions used as methodologies to orient and educate practitioners $3.18(63.6 \%)$ and all detail results with all cores explored in as explored in Table 4.

\section{DISCUSSION}

The general administration of Pharmaceutical Care established several programs including environmental culture and staff competency. ${ }^{[1-10,11]}$ It is a part of key elements of ISMP self-assessment of medication safety. [7] The pharmacy administration formulated social pharmacy committee with a membership of each region representative. The committee has a strategic plan for next years and implemented several projects. For instance; the pharmacist job satisfaction, patient pharmacy satisfaction system, pharmacy patient's bill of rights as part of environmental factors started in 2014. ${ }^{[12-14]}$ Another project related to pharmacy education was the hospital pharmacist competency or primary care pharmacist competency system, as part of staff competency released in 2014. All staff competency and satisfaction elements should report the results from all hospital pharmacies and primary care center pharmacies to $\mathrm{MOH}$ on an annual basis. The relationship between the environmental factors or staff competency and medication safety measured by ISMP self-assessment of medication safety. The authors used the tools at holy places and Makkah city to measure them.

The score of environmental factor result of our study was more than Vaida AJ et al. study in 2000 and the same results by Alen $2011 .{ }^{[8]}$ The finding expected that is due general Hajj executive committee and Medical affairs in Myakka city had a very comprehensive preparatory program before Hajj for all healthcare system during mass gathering including hospitals. The pharmacy services were one of the major and essential parts of the services. The staff competency results of our study were better than a study by Vaida AJ et.al. It is because the $\mathrm{MOH}$ had a very essential continuous medical education program for all health care professional, physicians, pharmacists, and nurses. ${ }^{[7]}$ 


\begin{tabular}{|c|c|c|c|c|c|}
\hline No. & Strategic Goals & $\begin{array}{l}\text { CBAHI } \\
\text { standards }\end{array}$ & $\begin{array}{l}\text { Suggestion for improvement during mass gathering } \\
\text { Hajj }\end{array}$ & $\begin{array}{l}\text { Propriety } \\
\text { scores }\end{array}$ & $\begin{array}{l}\text { Opportunity } \\
\text { scores }\end{array}$ \\
\hline 1 & \multicolumn{5}{|c|}{ Pharmacy computerization } \\
\hline 1.1 & Strategic Goal 3 & MM.3 & Expand electronic CME lecture for all pharmacist and clinical pharmacist & 3 & 5 \\
\hline 2 & \multicolumn{5}{|c|}{ Pharmacy human resources } \\
\hline 2.1 & \multirow{7}{*}{ Strategic Goal 2} & \multirow{7}{*}{$\begin{array}{l}\text { MM.2 } \\
\text { MM.3 }\end{array}$} & $\begin{array}{l}\text { Increase pharmacist workforce during mass gathering hajj period at 2-3 } \\
\text { three times incremental of } \mathrm{MOH} \text { standards }\end{array}$ & 5 & 3 \\
\hline 2.2 & & & Increase number of qualified, trained nurses & 5 & 3 \\
\hline 2.3 & & & $\begin{array}{l}\text { Implement education courses for pharmacist and nurses of new technology } \\
\text { system }\end{array}$ & 5 & 5 \\
\hline 2.4 & & & Increase number of qualified clinical pharmacist with different specialties & 5 & 3 \\
\hline 2.5 & & & $\begin{array}{l}\text { Apply the mass gathering pharmaceutical care orientation program for } \\
\text { pharmacist, pharmacy technician, and clinical pharmacist }\end{array}$ & 5 & 5 \\
\hline 2.6 & & & $\begin{array}{l}\text { Apply the mass gathering Pharmaceutical Care orientation for physician } \\
\text { and nurse }\end{array}$ & 5 & 5 \\
\hline 2.7 & & & $\begin{array}{l}\text { Continue with basic medication safety to Physician and nurse and } \\
\text { pharmacist }\end{array}$ & 5 & 5 \\
\hline 3 & \multicolumn{5}{|c|}{ Pharmacy innovation and empowering culture } \\
\hline 3.1 & \multirow[b]{2}{*}{ Strategic Goal 4} & \multirow{2}{*}{$\begin{array}{c}\text { MM.5 } \\
\text { MM.25 } \\
\text { MM.35 } \\
\text { MM.37 } \\
\text { MM.39 }\end{array}$} & Open position ambulatory care clinic for pharmacist for diabetes and asthma & 3 & 3 \\
\hline 3.2 & & & $\begin{array}{l}\text { Implement clinical pharmacy program for critical care, and infectious } \\
\text { diseases }\end{array}$ & 4 & 4 \\
\hline 4 & \multicolumn{5}{|c|}{ Pharmacy clinical audit } \\
\hline 4.1 & \multirow{6}{*}{ Strategic Goal 5} & \multirow{6}{*}{$\begin{array}{c}\text { MM.6 } \\
\text { MM.12 } \\
\text { MM.40 } \\
\text { MM.41 }\end{array}$} & $\begin{array}{l}\text { Annual survey of ISMP with emphasis on pharmacy environment and } \\
\text { staff competency }\end{array}$ & 5 & 5 \\
\hline 4.2 & & & Annual report of pharmacy staff competency & 4 & 4 \\
\hline 4.3 & & & Annual report of pharmacy environment culture & 5 & 4 \\
\hline 4.4 & & & Implement the pharmacy staff competency key performance indicators & 4 & 3 \\
\hline 4.5 & & & $\begin{array}{l}\text { Implement pharmacy environmental culture and design key performance } \\
\text { indicators }\end{array}$ & 5 & 5 \\
\hline 4.6 & & & Implement the competency indicators of type clinical pharmacist & 4 & 4 \\
\hline
\end{tabular}

Recently, $\mathrm{MOH}$ changes all educational program as through the internet. ${ }^{[15]}$ The authors revised all statement of environmental factors and staff competency key elements and suggested several points to improve both elements and meet pharmacy strategic goals and Saudi center of healthcare organizations accreditation (CIBAHI), priorities, and facilities during implementation. For instance, increase pharmacist workforce during mass gathering hajj period at 2-3 three times incremental of $\mathrm{MOH}$ standards, implement pharmacy staff competency key performance indicators, and implement the competency indicators of type clinical pharmacist, for more detail of recommendation as explored in Table 5.

\section{CONCLUSION}

The environment factors and staff competency key elements acceptable scoring level. It highly recommended continuing improving the medication safety culture. The ISMP is good measurements tools of medication safety and environmental culture relationship. In addition to medication safety and staff competency relationships.

\section{ACKNOWLEDGEMENT}

I want to thank all directors of pharmacies at all hospitals in Makkah region for their cooperation and filled the survey.

\section{CONFLICT OF INTEREST}

None

\section{ABBREVIATIONS USED}

GAPC: General administration of Pharmaceutical Care, CBAHI: Saudi Central Board for Accreditation for Health Care Institutions, MOH: Ministry of Health, ISMP: Institution Safe Medication Practice. 
Alomi et al.: Medication Safety during Hajj: Environmental culture and staff competency.

\section{REFERENCES}

1. Alomi YA. National Primary Care Pharmacist Competency System at $\mathrm{MOH}$ in Saudi Arabia. J Pharm Pharm Sci. 2016;1(4):1-5.

2. Alomi YA. National Primary Care Pharmacist Competency System at $\mathrm{MOH}$ in Saudi Arabia. J Pharm Pharm Scien. 2016;1(4):1-5.

3. Alomi YA, A new Guidelines on Hospital Pharmacy Manpower in Saudi Arabia. J Pharm Pract Community Med.2016;2(2): 30-31.

4. Alomi YA. Primary Care Center Pharmacy Manpower New Guidelines in Saudi Arabia. J Pharmacol Clin Res. 2016;1(1).

5. Alomi YA. National Medication Safety Program at Ministry of Health in Saudi Arabia. J Pharmacovigil.2015;3:5.

6. Alomi YA, National Mass Gathering Pharmaceutical Care Program at $\mathrm{MOH}$ in Saudi Arabia. J Pharm Pract Community Med. 2016;2(3):102-3.

7. Institute for Safe Medication Practices. 2011 ISMP Medication Safety SelfAssessment for Hospitals, Key Definitions. 2011;1-4. Available from: http:// ismp.org/selfassessments/Hospital/2011/definitions.pdf

8. Vaida AJ, Lamis RL, Smetzer JL, Kenward K, Cohen MR. Assessing the state of safe medication practices using the ISMP Medication Safety SelfAssessment $₫$ for hospitals: 2000 and 2011. The Joint Commission Journal on Quality and Patient Safety. 2014;40(2):51-AP3.

9. Smetzer JL, Vaida AJ, Cohen MR, Tranum D, Pittman MA, Armstrong CW.
Findings from the ISMP Medication Safety Self-Assessment ${ }^{\circledR}$ for Hospitals Jt Comm J Qual Saf. 2003;29(11):586-97.

10. Lesar T, Arnold Mattis P, Ernest Anderson E, Jean Avery M, John Fields Jill Gregoire R, Allen Vaida C. Using the ISMP Medication Safety SelfAssessment TM to Improve Medication Use Processes Patient Safety Article-at-a-Glance. Jt Comm J Qual Saf. 2003;29(5):211-26.

11. Alomi YA, Alghamdi SJ, Alattyh RA. Strategic Plan of General Administration of Pharmaceutical Care at Ministry of Health in Saudi Arabia 2012-2022. J Pharm Pharm Sci. 2015;1(3):1-8.

12. Alomi YA. National Pharmacy Administration Programs at Ministry of Health in Saudi Arabia. BAOJ Pharm Sci.2015;1(9).

13. Alomi YA, Al-Ghuraybi BI, Aloumi BE A-SR. Communications and relationship factors on pharmacy career satisfaction in Saudi Arabia. Value Heal. 2017;20(5):A1-383.

14. Alomi YA. Patient satisfaction of pharmaceutical care system at Ministry of Health in Saudi Arabia. BAOJ Pharm Sci. 2016;2(1).

15. Alomi YA, Kurdy L, Aljarad Z, Basudan H, Almekwar B, Almahmood S. Patient satisfaction of pharmaceutical care of primary care centers at Ministry of Health in Saudi Arabia. J Pharm Pract Community Med. 2016;2(23):79-87.

16. Alomi YA. Pharmacy Patient's Bill of Rights in Saudi Arabia. UK J Pharm Biosci. 2016:4(2):66.

17. Ministry of Health. Academic Affairs and Training General Department. Available from: http://learn.moh.gov.sa/login/index.php.

Cite this article as: Alomi YA, Khayat NAY, Baljoon MJ, Bamagaus YA, Jumah HMA. National Survey of Hospital Medication Safety Practice during Mass Gathering (Hajj-2016) in Makkah, Saudi Arabia: Environmental Culture and Staff Competency J Pharm Pract Community Med. 2017;3(4s):S15-S21. 